\title{
Inhibition of the c-Jun N-Terminal Kinase Signaling Pathway by the Mixed Lineage Kinase Inhibitor CEP-1347 (KT7515) Preserves Metabolism and Growth of Trophic Factor-Deprived Neurons
}

\author{
Charles A. Harris, ${ }^{1}$ Mohanish Deshmukh, ${ }^{1}$ Brian Tsui-Pierchala, ${ }^{1}$ Anna C. Maroney, ${ }^{3}$ and \\ Eugene M. Johnson $\mathrm{Jr}^{1,2}$ \\ Departments of ${ }^{1}$ Molecular Biology and Pharmacology and ${ }^{2}$ Neurology, Washington University, St. Louis, Missouri 63110, \\ and ${ }^{3}$ Cephalon, West Chester, Pennsylvania 19380
}

Nerve growth factor (NGF) deprivation triggers metabolic changes in sympathetic neurons that precede cell death. Here, we investigate the role of the c-Jun N-terminal kinase (JNK) pathway in downregulating neuronal metabolism. We show that, in the presence of CEP-1347 (KT7515), a small molecule known to block cell death upstream of JNK, cellular metabolism is preserved in neurons deprived of NGF. Biochemical data that are presented are consistent with the mechanism of action of CEP-1347 being the inhibition of the mixed lineage kinases (MLKs), known activators of JNK signaling. We demonstrate that CEP-1347-saved neurons continue to grow even in the absence of NGF, indicating that inhibition of the JNK pathway is permissive for neuronal growth in the absence of trophic support. These trophic effects are seen despite the fact that CEP1347 does not stimulate several known survival kinase pathways. In addition to blocking Bax-dependent cytochrome $c$

Target-derived neurotrophic factors are major determinants of whether neurons undergo programmed cell death (PCD) during development (Oppenheim, 1991). The availability of targetderived neurotrophic factors governs life or death in these populations, which include sympathetic neurons. PCD can be mimicked in vitro by removing nerve growth factor (NGF) from cultures of sympathetic neurons from perinatal animals. Removal of NGF triggers changes in signal transduction pathways, resulting in the activation of the transcription factor c-Jun, translocation of the pro-apoptotic molecule BAX from the cytoplasm to the mitochondria, the release of cytochrome $c$ from mitochondria, and the activation of caspases [see Putcha et al. (1999) and references within]. Neurons arrested at distal checkpoints in the cell death pathway undergo several metabolic changes (Deshmukh et al., 1996; Deckwerth et al., 1998), including decreases in the rates of protein synthesis, RNA synthesis, glucose uptake, and mitochondrial activity. Thus, blocking cell death with either Bax deficiency or caspase inhibitors results in metabolically compro-

Received June 7, 2001; revised Oct. 18, 2001; accepted Oct. 18, 2001.

This work was supported by National Institutes of Health Grants AG12947 and NS38651 to E.M.J. We thank members of the Johnson lab for valuable discussion and comments on this manuscript.

Correspondence should be addressed to E. M. Johnson Jr., Department of Molecular Biology and Pharmacology, Washington University School of Medicine, 4566 Scott Avenue, Box 8103, St. Louis, MO 63110. E-mail: ejohnson@pcg. wustl.edu.

M. Deshmukh's present address: Department of Cell Biology, University of North Carolina, Chapel Hill, NC 27599.

Copyright (C) 2001 Society for Neuroscience $\quad 0270-6474 / 01 / 220103-11 \$ 15.00 / 0$ release, the inhibition of the JNK signaling pathway with CEP1347 also blocks the development of competence-to-die in response to cytosolic cytochrome $c$. Therefore, inhibition of the JNK signaling pathway with the MLK inhibitor CEP-1347 inhibits both limbs of the apoptotic pathway. Finally, we demonstrate that neurons that have been NGF-deprived long-term but that have been kept alive by caspase inhibitors can be rescued metabolically by CEP-1347 as assessed by soma size, cytochrome $c$ localization, and protein synthesis rates. Therefore, we conclude that, in addition to converting extracellular signals into decisions of life and death, the JNK pathway can modulate cellular metabolism directly and thereby maintain not only survival but the "quality of life" of neurons.

Key words: apoptosis; JNK; MLK; NGF; sympathetic neurons; neurotrophism

mised neurons. Upstream of the BAX and caspase checkpoints the pro-apoptotic c-Jun N-terminal kinase (JNK) pathway is activated as demonstrated by immunohistochemistry with antibodies specific for phospho-c-Jun, as well as by in vitro kinase assays (Virdee et al., 1997; Eilers et al., 1998). c-Jun activity is required for NGF deprivation-induced death because both blocking antibodies and dominant-negative c-Jun constructs block death when injected into neurons (Estus et al., 1994; Ham et al., 1995). Microinjection techniques do not allow us to assess metabolic parameters in cells saved by these experimental manipulations. Therefore, the effect of inhibiting the JNK pathway on the metabolic status of trophic factor-deprived neurons is unknown.

CEP-1347 has neuroprotectant activity in a number of neuronal cell types, including sensory, sympathetic, and motor neurons (Borasio et al., 1998; Maroney et al., 1998, 1999). The fact that CEP-1347 suppressed trophic factor withdrawal-induced JNK1 activity in motor neurons (Maroney et al., 1998), coupled with the inability of CEP-1347 to inhibit JNK activity in vitro, indicates that CEP-1347 inhibits a kinase that lies upstream of JNK. Multiple kinases have been found to act upstream in JNK activation, but the physiologically relevant activators of JNK in neuronal death are still unknown. Recently, the mixed lineage kinase (MLK) family was identified as targets of CEP-1347. CEP-1347 inhibits c-Jun phosphorylation induced by MLKs as well as MLK activators such as cdc42 but has little or no effect on other known JNKKK such as ASK1 or MEKK1 (Maroney et al., 2001).

To assess the role of the JNK pathway on the catabolic effects 
of trophic factor deprivation, we have investigated the status of sympathetic neurons deprived of NGF in the presence of CEP1347. Unlike neurons deprived of NGF in the presence of caspase inhibitors or Bax deficiency, CEP-1347-saved neurons did not undergo dramatic falls in metabolic activity as measured by rates of protein synthesis, 3-(4,5-dimethylthiazol-2-yl)-2,5-diphenyltetrazolium bromide (MTT) reduction, and glucose transport. These results indicate that JNK signaling directly or indirectly depresses metabolic rates in neurons. Importantly, CEP-1347, like NGF, can reverse the loss of mitochondrial cytochrome $c$ and the metabolic dysfunction and atrophy in trophic factor-deprived neurons that have been kept alive with caspase inhibitors. Finally, whereas caspase inhibitor or Bax deficiency-saved neurons undergo a striking atrophy after NGF withdrawal, neurons deprived of NGF in the presence of CEP-1347 not only maintain somal diameter but continue to grow. Thus, we conclude that CEP-1347 mimics both the survival-promoting and trophic effects of neurotrophic factors and that sustained activation of the JNK pathway is required for the catabolic effects on cellular metabolism and atrophy as well as the death associated with trophic factor deprivation.

\section{MATERIALS AND METHODS}

Reagents. Unless indicated, all reagents were obtained from Sigma (St. Louis, MO). A 4 mM solution of CEP-1347 was diluted with MEM plus $1 \%$ BSA to make a working stock of $40 \mu \mathrm{M}$. The working stock was diluted accordingly for the demands of each experiment.

Primary sympathetic neuronal cultures. Cultures of sympathetic neurons were prepared as described previously (Johnson and Argiro, 1983). Briefly, superior cervical ganglia (SCG) were dissected from postnatal day 1 (P1) rats. SCG were treated sequentially with $1 \mathrm{mg} / \mathrm{ml}$ type IV collagenase and $2.5 \mathrm{mg} / \mathrm{ml}$ trypsin (Worthington Biochemicals, Freehold, $\mathrm{NJ}$ ) for $30 \mathrm{~min}$ each at $37^{\circ} \mathrm{C}$, followed by trituration through a firepolished glass Pasteur pipette. Neurons were plated in the appropriate medium. For metabolic experiments 5000-10,000 neurons were plated per well in 24-well dishes (Costar, Pleasanton, CA). For somal diameter experiments 2500 neurons per well were plated on 24-well dishes. For immunohistochemistry experiments 2500 neurons per well were plated on two-well chamber slides (Nalge Nunc, Naperville, IL). For microinjection experiments 2500 cells were plated on $35 \mathrm{~mm}$ dishes; the microinjection experiments were performed as described previously (Deshmukh and Johnson, 1998). All dishes were coated with collagen prepared from rat tail tendons. All NGF deprivation experiments were performed by washing 5-6 d in vitro (DIV) cultures with NGF-free medium and then adding anti-NGF neutralizing antibodies. Rescue experiments were performed by extensively washing cultures (to remove all neutralizing antibodies) and then adding the appropriate rescue medium. Rescue was performed in the presence of the pan-caspase inhibitor boc-aspartyl $(O \mathrm{Me})$ fluoromethylketone (BAF; Enzyme Systems, Livermore, CA) to prevent any death that might occur after disinhibition of caspases.

Media. Except as indicated, neurons were plated into AM50 consisting of MEM (Life Technologies, Gaithersburg, MD), 10\% fetal bovine serum (Harlan, Indianapolis, IN), $2 \mathrm{~mm}$ glutamine, and $20 \mu \mathrm{M}$ 5-fluoro$2^{\prime}$-deoxyuridine plus $20 \mu \mathrm{M}$ uridine, $100 \mathrm{U} / \mathrm{ml}$ penicillin, $100 \mu \mathrm{g} / \mathrm{ml}$ streptomycin, and $50 \mathrm{ng} / \mathrm{ml} 2.5 \mathrm{~S} \mathrm{NGF}$ (Harlan). At the time of plating 3.3 $\mu \mathrm{g} / \mathrm{ml}$ aphidicolin (A.G. Scientific, San Diego, CA) was added to reduce the number of non-neuronal cells further. Because the presence of serum increases the required concentration of CEP-1347 to achieve bioactivity (Maroney et al., 1999), deprivation experiments were performed in serum-free medium. A modified N2 medium was used for these experiments consisting of DMEM/F12, $40 \mathrm{~nm}$ progesterone, $30 \mathrm{~nm}$ sodium selenite, $100 \mu \mathrm{M}$ putrescine, and $10 \mu \mathrm{g} / \mathrm{ml}$ transferrin (Jackson ImmunoResearch, West Grove, PA). Insulin was deleted from the traditional N2 medium because insulin supports the survival and metabolism of sympathetic neurons (Recio-Pinto et al., 1986).

Immunohistochemistry. Neuronal cultures were immunostained as described previously (Easton et al., 1997). Briefly, neurons were grown on two-well glass chamber slides in the appropriate medium. Cultures were washed once with PBS and fixed with freshly made $4 \%$ paraformaldehyde in PBS at $4^{\circ} \mathrm{C}$ for $30 \mathrm{~min}$. Cultures then were washed with Tris-buffered saline (TBS; $100 \mathrm{~mm}$ Tris- $\mathrm{HCl}, \mathrm{pH} 7.6$, and $0.9 \% \mathrm{NaCl}$ ) three times and exposed to permeabilization/blocking solution (TBS containing 5\% goat serum and $0.3 \%$ Triton $\mathrm{X}-100$ ) for $30 \mathrm{~min}$ at room temperature. For cytochrome $c$ staining the slides were incubated in anti-cytochrome $c$ primary antibody (PharMingen, San Diego, CA) solution overnight at $4^{\circ} \mathrm{C}$. The primary antibody was diluted 1:1000 (final concentration, 0.5 $\mu \mathrm{g} / \mathrm{ml}$ ) in TBS containing $1 \%$ goat serum and $0.3 \%$ Triton X-100. Cultures were washed three times with TBS and incubated in an antimouse Alexa488-conjugated secondary antibody (Molecular Probes, Eugene, OR) solution for $2-4 \mathrm{hr}$ at $4^{\circ} \mathrm{C}$. The secondary antibody was diluted 1:300 (final concentration, $2 \mu \mathrm{g} / \mathrm{ml}$ ) in TBS containing $1 \%$ goat serum and $0.3 \%$ Triton $\mathrm{X}-100$. Cultures were washed twice in TBS and stained with the nuclear dye bisbenzimide (Hoechst 33258 used at $1 \mu \mathrm{g} / \mathrm{ml}$; Molecular Probes) for $15 \mathrm{~min}$ at room temperature. Cells were washed twice with TBS, mounted with a coverslip, and examined by fluorescence microscopy by a naive observer. For phospho-c-Jun immunofluorescence, phospho-c-Jun Serine-63 (New England Biolabs, Beverly, MA) was the primary antibody (1:400), and donkey $\mathrm{Cy}-3$ anti-rabbit (Molecular Probes) was used as the secondary antibody (1:300).

Immunoprecipitation and immunoblotting. Lysates were prepared from treated neurons in Laemmli sample buffer and electrophoresed on Novex Tris-glycine gels (Invitrogen, San Diego, CA). Gels were transferred onto polyvinylidene difluoride, blocked, and exposed to primary antibody, washed, exposed to secondary antibody, washed, and then developed with SuperSignal detection system (Pierce, Rockford, IL). Primary antibodies were phospho-Akt (Serine-473) and phospho-Erk (Cell Signaling Technology, Beverly, MA). Immunoprecipitation was performed as described previously (Encinas et al., 2001).

Rate of protein synthesis. Protein synthesis assays were performed as described previously (Deckwerth and Johnson, 1993). Briefly, SCG cultures were washed with PBS and labeled for $4 \mathrm{hr}$ at $37^{\circ} \mathrm{C}$ with $5-10$ $\mu \mathrm{Ci} / \mathrm{ml}$ Tran ${ }^{35} \mathrm{~S}$-label $(>1000 \mathrm{Ci} / \mathrm{mmol}$; ICN Pharmaceuticals, Costa Mesa, CA) in medium lacking cysteine and methionine (Washington University School of Medicine Tissue Culture Center, St. Louis, MO). Cultures were washed with PBS and lysed with $500 \mu \mathrm{l}$ of a solution containing $0.5 \%$ SDS, $1 \mathrm{~mm}$ EDTA, and $10 \mathrm{~mm}$ Tris-HCl, pH 7.5. Protein was precipitated with $10 \%$ trichloroacetic acid on ice and bound via filtration to a nitrocellulose filter (BA-85, Schleicher \& Schuell, Keene, NH). The filter was washed with ice-cold $10 \%$ trichloroacetic acid, and its radioactivity was measured in a liquid scintillation counter.

Rate of MTT reduction. SCG cultures were washed with PBS once and incubated in L-15 plus $10 \%$ FBS containing $0.4 \mathrm{mg} / \mathrm{ml}$ MTT for $10 \mathrm{~min}$ at $37^{\circ} \mathrm{C}$. Cultures were washed with PBS; the tetrazolium salts were solubilized in $200 \mu \mathrm{l}$ of DMSO and measured for absorbance (550-650 nM) on a Molecular Devices Thermomax microplate reader (Sunnyvale, CA).

Rate of 2-deoxyglucose uptake. Neuronal cultures were washed three times with warm PBS and labeled for $10 \mathrm{~min}$ at $37^{\circ} \mathrm{C}$ with $2.5 \mu \mathrm{Ci} / \mathrm{ml}$ 2-deoxy-D-[2,6- $\left.{ }^{3} \mathrm{H}\right]$-glucose in MEM medium containing 100-300 $\mu \mathrm{M}$ D-glucose. The cultures were washed three times with PBS containing 25 $\mathrm{mM}$ glucose (to inhibit additional transport) and lysed with $500 \mu \mathrm{l}$ of a solution containing 1\% SDS, $1 \mathrm{~mm}$ EDTA, and $10 \mathrm{~mm}$ Tris-HCl, $\mathrm{pH}$ 7.5. The radioactivity of the lysate was measured in a liquid scintillation counter.

Somal diameter and viability. Cell size was measured by projecting phase-contrast micrographs of neurons. Although the majority of neurons appeared round, morphological eccentricity was taken into account by measuring a major axis and minor axis and computing the square root of the product of the two. Measurements were acquired in a blinded manner, and $>100$ somata were measured per data point. Neuronal viability measurements were performed as described previously (Deckwerth and Johnson, 1993). Briefly, neuronal cultures were fixed with $4 \%$ paraformaldehyde stained with crystal violet and were counted.

Data analysis. For survival and metabolic assays the experiments were performed three times. Each experiment was performed in quadruplicate per condition per repetition. The data are plotted as mean \pm SD. Statistical significance was assessed by Student's $t$ test. Immunohistochemistry experiments were performed three times in duplicate per condition. Microinjection experiments were performed twice.

\section{RESULTS}

\section{CEP-1347 blocks JNK activation after NGF deprivation and is a potent long-term protectant of sympathetic neurons}

To determine whether CEP-1347 was acting upstream of JNK activation, we switched neurons (5 DIV) to serum-free medium 

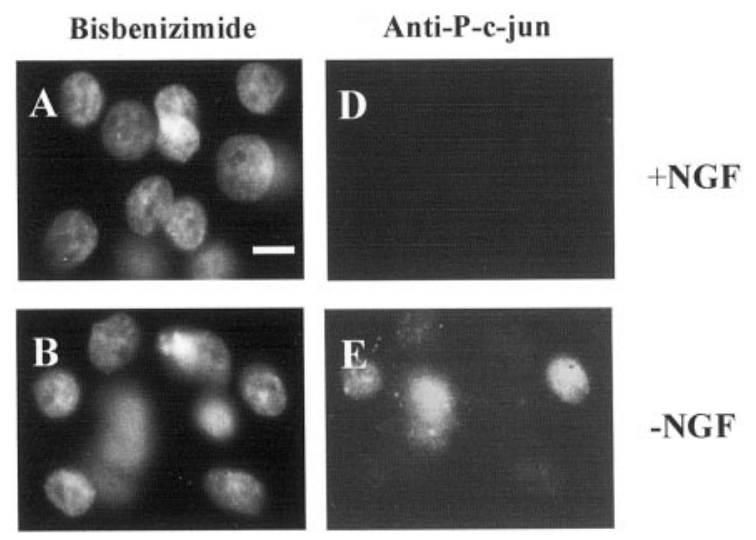

-NGF
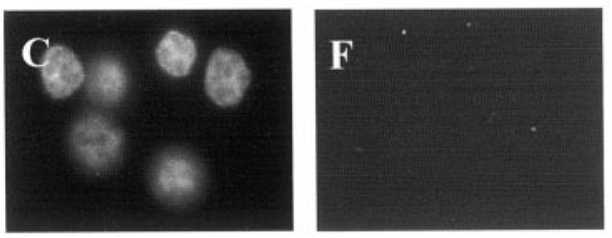

\section{-NGF + CEP1347}

Figure 1. CEP-1347 blocks c-Jun phosphorylation after NGF deprivation. Neurons were maintained in $\operatorname{NGF}(A, D)$, deprived of NGF $(B, E)$, or deprived of NGF in the presence of CEP-1347 $(C, F)$ for $8 \mathrm{hr}$. Nuclei were stained with Hoechst $33258(A-C)$, and immunohistochemistry was performed in parallel with an antibody specific for c-Jun that was phosphorylated at Serine residue $63(D-F)$. Robust staining was seen in cultures deprived of NGF, but not in NGF-maintained cultures or NGFdeprived CEP-1347-treated cultures. Scale bar, $10 \mu \mathrm{m}$.

containing $50 \mathrm{ng} / \mathrm{ml} \mathrm{NGF}$ or deprived them of NGF in the presence or absence of $500 \mathrm{~nm}$ CEP-1347 for $8 \mathrm{hr}$, at which time immunohistochemistry was performed with an antibody that specifically recognizes c-Jun phosphorylated at Serine residue 63. Nuclei were stained with bisbenzimide. No nuclear changes characteristic of apoptosis were seen in any conditions at this early time point (Fig. $1 A-C$ ). No phospho-c-Jun staining was seen in NGF-maintained cultures (Fig. 1D); however, in neurons deprived of NGF for $8 \mathrm{hr}$ there was marked nuclear phospho-c-Jun staining in $\sim 50 \%$ of neurons (Fig. $1 E$ ). No neurons deprived of NGF in the presence of CEP-1347 were phospho-c-Jun-positive (Fig. $1 F$ ). Therefore, CEP-1347 acts upstream of c-Jun phosphorylation. We went on to perform experiments to determine the effects of blocking c-Jun phosphorylation on neuronal survival. Sympathetic neurons were grown in AM50 for $5 \mathrm{~d}$. On the fifth day the neurons were switched to N2 media containing $50 \mathrm{ng} / \mathrm{ml}$ NGF or N2 containing neutralizing NGF antibodies and 0, 25, 50, 100, 200, 400, or 800 nм CEP-1347. After 3 d neuronal viability was assessed. As shown in Figure 2D, CEP-1347 promotes the survival of NGF-deprived sympathetic neurons at nanomolar concentrations. The $\mathrm{EC}_{50}$ for promotion of survival was $125 \mathrm{~nm}$, with $43 \pm 5 \%$ survival at $100 \mathrm{~nm}$ and $100 \pm 5 \%$ survival at $200 \mathrm{~nm}$. The dose-response curve is consistent with that reported previously (Maroney et al., 1999). A representative photomicrograph of control neurons that were maintained in $50 \mathrm{ng} / \mathrm{ml} \mathrm{NGF}$ is shown in Figure $2 A$. Neurons deprived of NGF in the absence of CEP-1347 or in the presence of $500 \mathrm{~nm}$ CEP-1347 are shown in Figure 2, $B$ and $C$, respectively. Note that both the soma and the neuritic network are preserved in CEP-1347-saved neurons. Because NGF deprivation-induced death depends on macromolecular synthesis (Martin et al., 1988), it is important to demonstrate that pharmacological neuroprotectants in this model are not

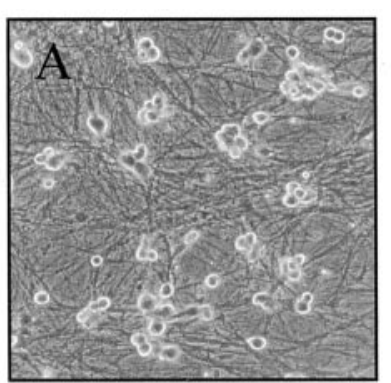

+ NGF

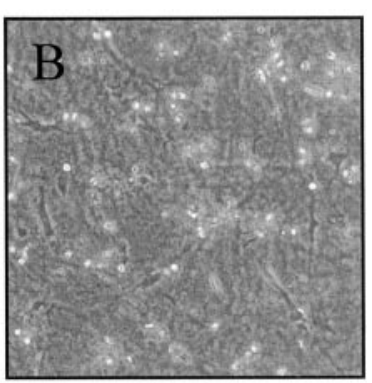

- NGF
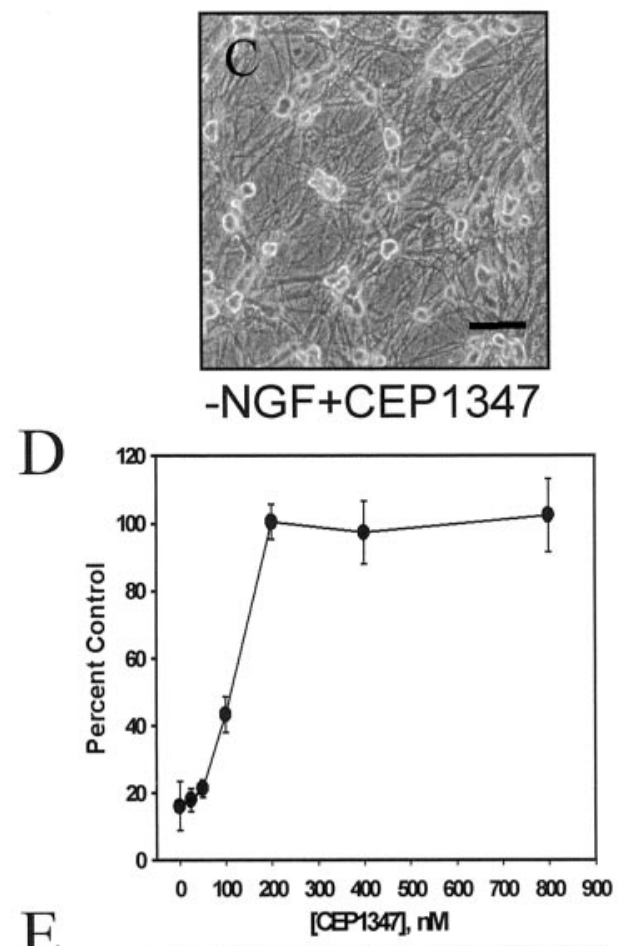

E

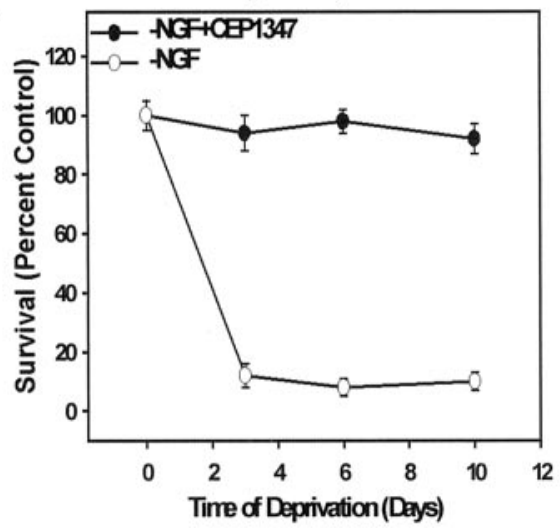

Figure 2. CEP-1347 is a potent long-term neuroprotectant and maintains both somal and neuritic morphology in sympathetic neurons. Neurons were grown in the presence of NGF for $5 \mathrm{~d}$ and then switched to media containing NGF $(A)$, no NGF $(B)$, or no NGF plus $500 \mathrm{~nm} \mathrm{CEP-1347}(C)$. Pictures were taken $3 \mathrm{~d}$ later. $D$, Sympathetic neurons were cultured in NGF for $5 \mathrm{~d}$ and then switched to serum-free medium containing $0,25,50$, $100,200,400$, or $800 \mathrm{~nm}$ CEP-1347. Neuronal viability was assessed $3 \mathrm{~d}$ later; $p<0.01$ for CEP-1347 $>50 \mathrm{~nm}$ versus no CEP-1347. E, CEP-1347 promotes long-term survival of NGF-deprived sympathetic neurons. Neurons were grown in the presence of NGF for $5 \mathrm{~d}$ and then deprived of NGF or deprived of NGF in the presence of $500 \mathrm{nM}$ CEP-1347 for the indicated time periods; $p<0.001$ for $-\mathrm{NGF}$ versus $-\mathrm{NGF}+\mathrm{CEP}-1347$ for all time points. Scale bar, $75 \mu \mathrm{m}$. 
acting by inhibiting protein synthesis. CEP-1347 did not inhibit protein synthesis in NGF-maintained cultures at the doses used throughout these studies (data not shown). Because many compounds provide only short-term neuroprotection (such compounds slow the death as opposed to blocking it completely), we assessed how long neurons could be maintained in the absence of NGF in the presence of CEP-1347. At 5 DIV the neurons either were maintained in $50 \mathrm{ng} / \mathrm{ml} \mathrm{NGF}$ or were deprived of NGF in the absence or presence of $400 \mathrm{nM}$ CEP-1347 for 3, 6, or $10 \mathrm{~d}$; the medium was changed every third day. CEP-1347 promotes the survival of virtually $100 \%$ of the neurons for as long as $10 \mathrm{~d}$ after NGF deprivation (Fig. 2E). Thus, we conclude that in the absence of the activation of the JNK signaling pathway the neurons are unable to execute cell death in response to trophic factor deprivation.

\section{CEP-1347 does not stimulate prosurvival signaling}

Because CEP-1347 is a K252a analog, we wanted to determine whether the apparent trophic effects of CEP-1347 could be attributed to TrkA agonist activity. Neurons were maintained in NGF, deprived of NGF for $1 \mathrm{hr}$, or deprived of NGF in the presence of CEP-1347 for 1 or $24 \mathrm{hr}$. The cultures were immunoprecipitated with a Trk antibody, and the immunoprecipitates were immunoblotted with phosphotyrosine antibodies. Figure $3 A$ shows that CEP-1347 has no effect on TrkA phosphorylation. CEP-1347 also did not stimulate the phosphorylation of Ret, the signaling component of the survival-promoting GDNF ligand family receptor complex (data not shown).

Because phosphatidylinositol 3-kinase (PI3-kinase) signaling has been implicated in neuronal survival, we wanted to determine whether CEP-1347-saved NGF-deprived neurons displayed active or inactive PI3-kinase activity. Neurons were maintained in NGF, deprived of NGF, or deprived of NGF in the presence of CEP1347. Immunoblotting with phospho-Akt antibodies indicated that strong Akt phosphorylation (indicative of PI3-kinase activity) was seen in NGF-maintained neurons but was absent or greatly reduced in both NGF-deprived neurons and NGFdeprived CEP-1347-saved neurons (Fig. 3B). Therefore,CEP1347 does not stimulate PI3-kinase activity, and neurons can survive in the absence of PI3-kinase signaling. Erk MAP kinase signaling also has been implicated in neuronal survival. Similar lysates were probed with antibodies specific to phosphorylated forms of Erk1 and 2. The strong Erk kinase activity seen in the presence of NGF was absent when neurons were deprived of NGF, and this loss of activity was unaffected by CEP-1347 (Fig. $3 C$ ). CEP-1347 also did not affect phospho-Erk or phosphoAkt levels in NGF-maintained neurons (data not shown). Therefore, CEP-1347 appears to act solely by inhibition of the JNK pathway, without directly or indirectly increasing activity of several known prosurvival pathways.

To determine whether MKK4, the enzyme immediately upstream of JNK, becomes phosphorylated during NGF deprivation and whether this phosphorylation is dependent on the action of MLKs, we maintained neurons in NGF or deprived neurons of NGF for $0.75,2,4$, or $8 \mathrm{hr}$ or deprived neurons of NGF for $8 \mathrm{hr}$ in the presence of CEP-1347 or maintained neurons in NGF in the presence of CEP-1347. Then the lysates were immunoblotted with an antibody specific to the phosphorylated form of MKK4. After NGF deprivation there was a gradual increase in the amount of phospho-MKK4 greater than twofold at $2 \mathrm{hr}$ after

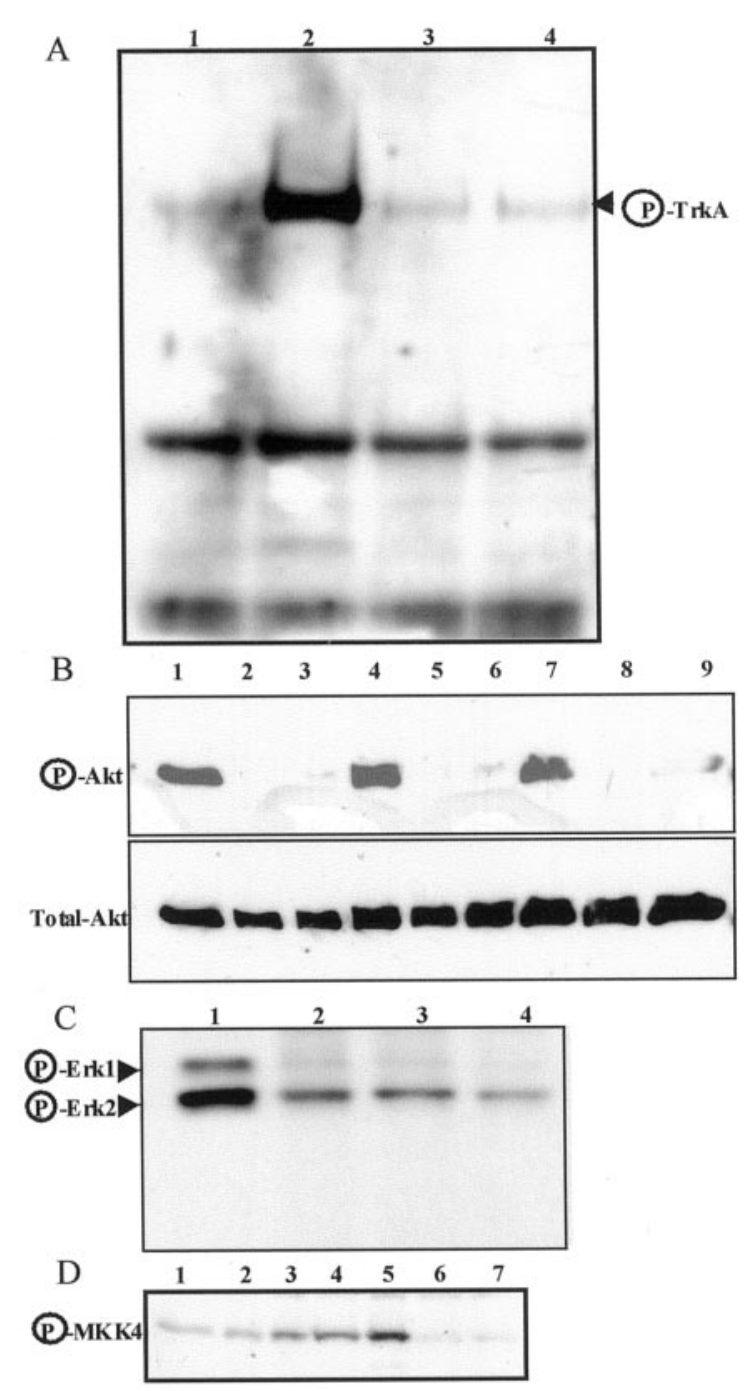

Figure 3. CEP-1347 blocks MKK4 phosphorylation and does not stimulate known survival kinase pathways. $A$, CEP-1347 does not stimulate TrkA. Neuronal lysates were subjected to immunoprecipitation with Trk antibody, followed by immunoblotting with phosphotyrosine antibody. Lane 1, Neurons deprived of NGF for $1 \mathrm{hr}$; lane 2, neurons maintained in NGF; lane 3, neurons deprived of NGF in the presence of CEP-1347 for $1 \mathrm{hr}$; lane 4, neurons deprived of NGF in the presence of CEP-1347 for 24 hr. $B$, CEP-1347 does not activate PI3-kinase activity. Lysates were prepared from NGF-maintained (lanes 1, 4, 7), NGF-deprived (lanes 2, 5, 8), or NGF-deprived CEP-1347-saved neurons (lanes 3, 6, 9) that were treated for 12 (lanes 1-3), 18 (lanes 4-6), or $24 \mathrm{hr}$ (lanes 7-9). Lysates were immunoblotted with phospho-Akt (Serine-473) antibodies. $C$, CEP1347 does not activate MAP Erk kinase activity. Lysates were blotted with antibodies that recognize phospho-Erks. Lane 1, NGF-maintained neurons; lane 2, neurons deprived of NGF for $1 \mathrm{hr}$; lane 3, neurons deprived of NGF but treated with CEP-1347 for $1 \mathrm{hr}$; lane 4, neurons deprived of NGF but treated with CEP-1347 for $24 \mathrm{hr}$. D, CEP-1347 blocks MKK4 phosphorylation induced by NGF deprivation. Neuronal lysates were immunoblotted with antibody specific to phospho-MKK4. Lane 1, NGF-maintained neurons; lane 2, neurons deprived of NGF for 45 min; lane 3, neurons deprived of NGF for $2 \mathrm{hr}$; lane 4, neurons deprived of NGF for $4 \mathrm{hr}$; lane 5, neurons deprived of NGF for $8 \mathrm{hr}$; lane 6, neurons deprived of NGF for $8 \mathrm{hr}$ in the presence of CEP-1347; lane 7, NGFmaintained neurons in the presence of CEP-1347.

deprivation and fourfold by $8 \mathrm{hr}$ after deprivation (Fig. 3D). NGF-deprived CEP-1347-treated neurons demonstrated no increase in phospho-MKK4 levels and, in fact, had less phosphoMKK4 than NGF-maintained neurons (Fig. 3D). 

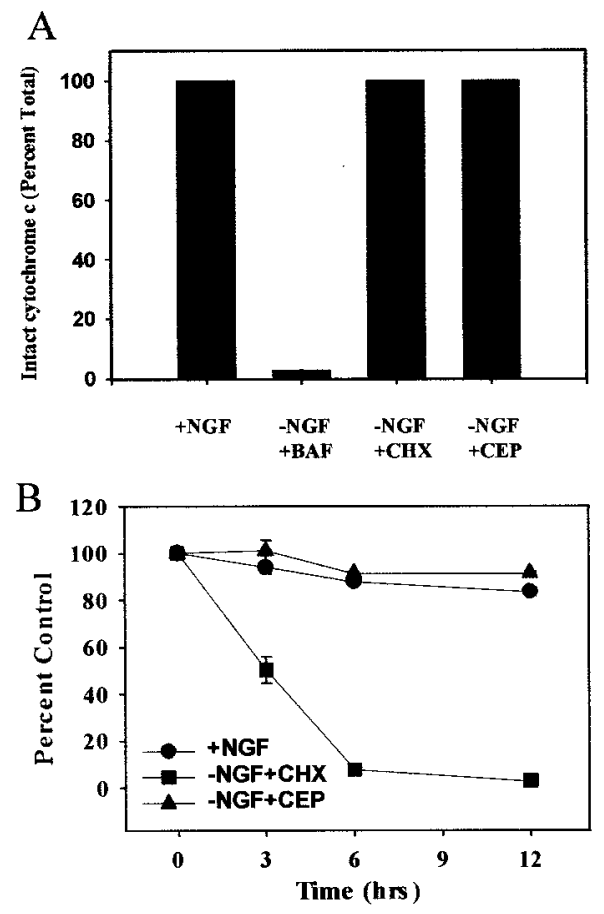

Figure 4. CEP-1347 blocks the release of cytochrome $c$ and the development of competence. $A$, Neurons were maintained in NGF for $5 \mathrm{~d}$ and then either refed with NGF $(+N G F)$ or deprived of NGF in the presence of the pan-caspase inhibitor BAF $(-N G F+B A F)$, cycloheximide $(-N G F+C H X)$, or CEP-1347 $(-N G F+C E P)$ for $48 \mathrm{hr}$. Cells were fixed and processed for immunohistochemistry to stain for cytochrome $c$ as described in Materials and Methods. $B$, Rat sympathetic neurons (5 DIV) were maintained in NGF $(+N G F)$, were deprived of NGF in the presence of cycloheximide $(-N G F+C H X)$, or were deprived of NGF in the presence of $400 \mathrm{~nm}$ CEP-1347 $(-N G F+C E P)$ for $36 \mathrm{hr}$. Then the cells were microinjected with cytochrome $c(5 \mathrm{mg} / \mathrm{ml})$ along with rhodamine dextran. The viability of microinjected cells was determined at various times after the injections; $p<0.01$ for $-\mathrm{NGF}+\mathrm{CHX}$ versus $-\mathrm{NGF}+$ CEP-1347 at all time points.

\section{CEP-1347 blocks both limbs of the cell death pathway: cytochrome $c$ release and development of competence}

Neurons deprived of NGF release cytochrome $c$ before caspase activation (Neame et al., 1998). Therefore, neurons deprived of NGF but saved by caspase inhibitors release cytochrome $c$ such that $\sim 50 \%$ of cells have released cytochrome $c$ by $22 \mathrm{hr}$ after deprivation, with nearly all cells having released cytochrome $c$ by $36 \mathrm{hr}$ after deprivation (Deshmukh and Johnson, 1998). In contrast, the macromolecular synthesis inhibitor cycloheximide ( $\mathrm{CHX})$ aborts the cell death program at a point upstream of cytochrome $c$ release such that neurons deprived of NGF, but saved by $\mathrm{CHX}$, display intact cytochrome $c$ (Deshmukh and Johnson, 1998). We examined whether CEP-1347 blocked the sympathetic neuronal death pathway upstream or downstream of cytochrome $c$ release. We compared the status of cytochrome $c$ by immunohistochemistry in NGF-maintained cells with cells deprived of NGF in the presence of CHX, BAF, and CEP-1347. As reported previously, BAF-saved neurons lost cytochrome $c$ staining, whereas $\mathrm{CHX}$-saved neurons retain mitochondrial cytochrome $c$ staining. CEP-1347-saved cells displayed punctate cytochrome $c$ staining (Fig. $4 A$ ), demonstrating that CEP-1347 acts at a point upstream of cytochrome $c$ release.

To assess whether JNK signaling was required for the devel- opment of competence-to-die, we either maintained neurons in NGF or deprived them of NGF in the presence of $\mathrm{CHX}$ or CEP-1347 for $36 \mathrm{hr}$, a period by which competence fully develops. At this time the neurons were injected with $5 \mathrm{mg} / \mathrm{ml}$ cytochrome $c$ and rhodamine dextran. Neurons were counted immediately after injection and thereafter at 3, 6, 9, and $12 \mathrm{hr}$. Neurons that were maintained in NGF did not die after cytochrome $c$ injection, with $82 \%$ alive at $12 \mathrm{hr}$ after injection (Fig. $4 \mathrm{~B}$ ). In contrast, neurons that had been deprived of NGF in the presence of $\mathrm{CHX}$ underwent a rapid cell death such that $56 \%$ of neurons were alive at $3 \mathrm{hr}$ and only $4 \%$ percent were alive at $12 \mathrm{hr}$ after injection (Fig. 4B). Neurons that had been deprived of NGF in the presence of CEP-1347 resembled the NGF-maintained neurons; $91 \%$ percent were alive at $12 \mathrm{hr}$ (Fig. 4B). Therefore, CEP-1347 blocks the development of competence-to-die in sympathetic neurons deprived of NGF.

\section{CEP-1347 maintains the metabolic function and growth of NGF-deprived sympathetic neurons}

Protein synthesis rates were determined in cells maintained in 50 $\mathrm{ng} / \mathrm{ml}$ NGF or deprived of NGF in the presence of CEP-1347 or BAF. At $36 \mathrm{hr}$ after NGF deprivation the protein synthesis rates of neurons were assessed. In contrast to BAF-saved cells that had protein synthesis rates $18 \%$ of control, CEP-1347-treated NGFdeprived neurons had protein synthesis rates $75 \%$ of control (data not shown). We next determined whether the effect of CEP-1347 to preserve protein synthesis decayed with time, despite promoting long-term survival. To assess whether this effect was temporary, we did a similar experiment using time points of 1, 2, and $3 \mathrm{~d}$ after deprivation. CEP-1347-maintained neurons continued to display protein synthesis rates significantly elevated above BAF-saved neurons. However, when compared with 50 ng/ml NGF-maintained cultures, CEP-1347-maintained cultures appear to decrease their protein synthesis rates slightly over time (Fig. 5B). Because the measurements at each time point are relative to neurons that were maintained in $50 \mathrm{ng} / \mathrm{ml} \mathrm{NGF}$ for the same amount of time and because these cultures are growing significantly (increasing somal diameter and extending neuritic processes), the ability of CEP-1347 to maintain protein synthesis rates is underestimated. If one looks at the absolute protein synthesis rates in the CEP-1347-maintained cultures over time, it is apparent that the protein synthesis rates actually are increasing over time, albeit not to the same extent as $50 \mathrm{ng} / \mathrm{ml} \mathrm{NGF-}$ maintained cultures (Fig. $5 A$ ).

Mitochondrial activity can be assessed by measuring the reduction of MTT, a measure of cellular dehydrogenase activity (Liu et al., 1997), or by the use of potential sensitive dyes (Nicholls and Ward, 2000). By both criteria, mitochondrial activity falls after NGF deprivation (Deckwerth and Johnson, 1993; Deshmukh et al., 2000). We determined whether these falls in mitochondrial activity occur in NGF-deprived CEP-1347-maintained cultures by using the MTT reduction assay. Neurons were grown in NGF for $5 \mathrm{~d}$ and then deprived of NGF in the presence of BAF or CEP-1347 for $36 \mathrm{hr}$; MTT assay was performed, and the values were compared with NGF-maintained cultures. NGF-deprived BAF-saved neurons underwent drastic falls in MTT reduction activity (12\% control; data not shown). In contrast, the CEP1347-maintained NGF-deprived cells displayed MTT rates $\sim 65 \%$ that of NGF-maintained cultures (data not shown). To determine again whether this was a temporary effect or whether CEP-1347-maintained cells plateau with regard to their metabolism, we compared the MTT reduction rates of NGF-deprived 

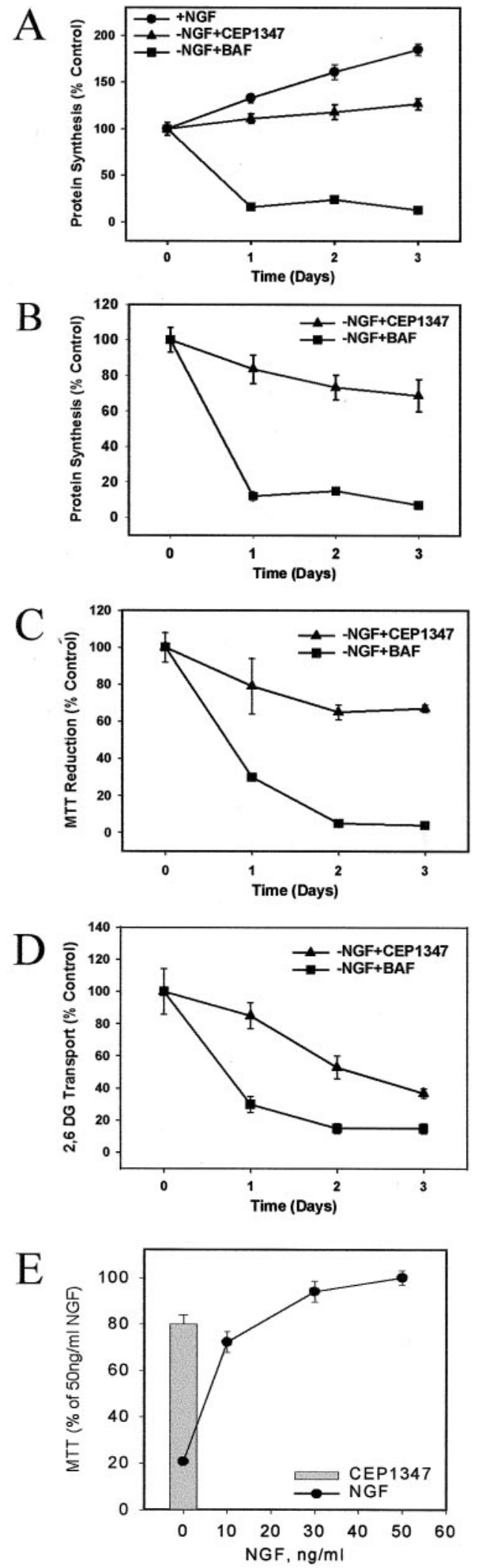

Figure 5. CEP-1347 maintains the metabolism of NGF-deprived neurons. $A$, Neurons were maintained in NGF for $5 \mathrm{~d}$, at which time they were switched to serum-free media containing NGF $(50 \mathrm{ng} / \mathrm{ml})$, BAF $(50 \mu \mathrm{M})$, or CEP-1347 (500 nM) for the specified times. At each time point the protein synthesis rates were measured as described in Materials and Methods, and the value of 5 DIV NGF-maintained cultures was taken as

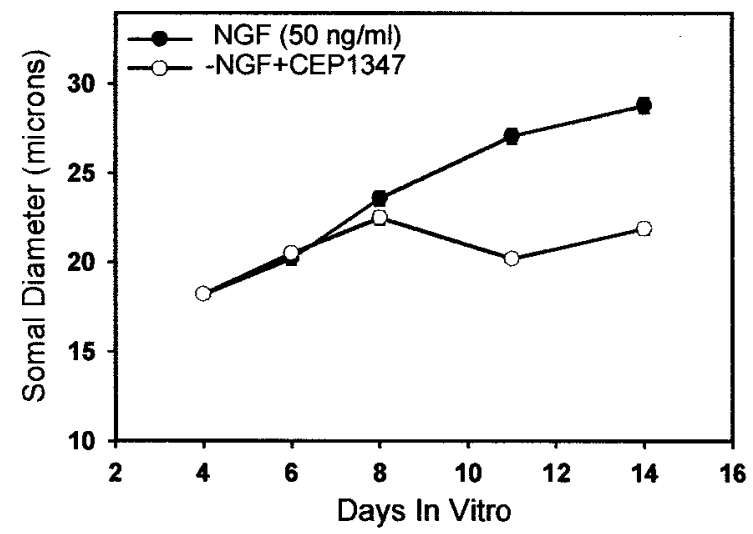

Figure 6. CEP-1347 promotes the growth of neurons in the absence of NGF. At 5 DIV sister cultures either were continued in $50 \mathrm{ng} / \mathrm{ml} \mathrm{NGF}$ or were deprived of NGF in the presence of $500 \mathrm{nM}$ CEP-1347. Somal diameters were measured as described in Materials and Methods.

CEP-1347-maintained cells at 1, 2, and 3 d. Again, MTT reduction rates of NGF-deprived CEP-1347-saved neurons did not remain as elevated as neurons grown in $50 \mathrm{ng} / \mathrm{ml} \mathrm{NGF}$, but on an absolute level the MTT reduction rates did not decrease and were much greater than those of NGF-deprived BAF-saved neurons (Fig. 5C).

We also determined whether CEP-1347-maintained NGFdeprived neurons maintain rates of glucose uptake. The 5 DIV neurons either were maintained in NGF or were deprived of NGF in the presence or absence of CEP-1347 for $24 \mathrm{hr}$, and glucose uptake was measured. Neurons deprived of NGF had depressed glucose uptake rates compared with NGF-maintained cultures. In contrast, neurons deprived of NGF in the presence of CEP-1347 displayed glucose rates that were not significantly different from NGF-maintained cultures (data not shown). To determine again whether the ability of CEP-1347 to maintain glucose rates was transient or long-lived, we extended the experiment to include time points of 1, 2, and $3 \mathrm{~d}$ after NGF deprivation. In contrast to the other metabolic parameters, glucose uptake was not maintained to the same extent. However, glucose uptake was still significantly greater in CEP-1347-maintained neurons than in BAF-saved neurons that were deprived of NGF (Fig. 5D).

The ability of CEP-1347 to maintain metabolic function of NGF-deprived neurons in contrast to cells saved by caspase inhibition or Bax deletion indicates that CEP-1347 exerts a trophic influence on neurons. To address this issue further, we examined the somal diameters of neurons that were maintained in NGF and compared them with those of neurons deprived of NGF maintained in CEP-1347 for several days (Fig. 6). As expected, sympathetic neurons continued to grow in the presence of NGF

$\leftarrow$

$100 \%$. The absolute protein synthesis rates of CEP-1347-treated cultures actually increase over time, albeit to a lesser extent than NGF-maintained cultures. $B$, Data plotted relative to NGF-maintained cultures of the same age. $C$, Neurons were treated identically as in $B$ but assayed for mitochondrial activity by measuring MTT reduction as described in Materials and Methods. $D$, Neurons were treated as in $B$, except that the cultures were assayed for 2,6-deoxyglucose transport as described in Materials and Methods. $E$, CEP-1347 treatment is equivalent to $\sim 15 \mathrm{ng} / \mathrm{ml} \mathrm{NGF}$. Neurons were grown in $50 \mathrm{ng} / \mathrm{ml}$ for $5 \mathrm{~d}$ and then switched to various amounts of NGF for $36 \mathrm{hr}$ ( filled circles). MTT reduction was measured. Vertical bar, CEP-1347 treatment with no NGF. $A-D, p<0.05$ for $-\mathrm{NGF}$ + BAF versus $-\mathrm{NGF}+\mathrm{CEP}-1347$ for all time points. 


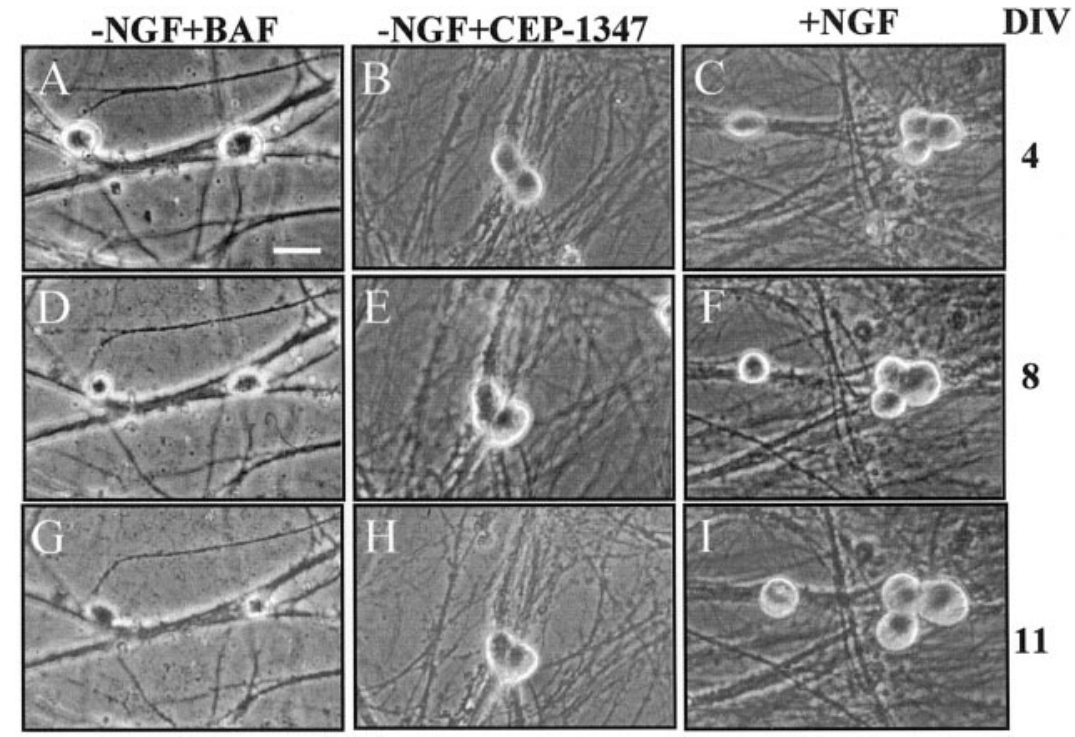

Figure 7. CEP-1347 prevents neuronal atrophy that occurs after NGF deprivation. Neurons (4 DIV) were maintained in $50 \mathrm{ng} / \mathrm{ml}$ NGF $(C, F, I)$, NGF-free medium plus caspase inhibitor BAF $(A, D, G)$, or NGF-free medium plus CEP$1347(B, E, H)$. Photomicrographs were taken at 4 DIV $(A-C), 8$ DIV $(D-F)$, and 11 DIV $(G-I)$. Scale bar, $20 \mu \mathrm{m}$. throughout the entire period that was examined. NGF-deprived cultures maintained in CEP-1347 continued to grow at a rate indistinguishable from NGF-maintained neurons for a period of 4 d. After that time the growth of CEP-1347-maintained NGFdeprived neurons plateaued, whereas NGF-maintained cultures continued to grow. These effects on somal diameter can be appreciated in high-power phase-contrast matched field photomicrographs of neurons grown over time in these conditions. Neurons that were maintained in NGF continue to grow (Fig. $7 C, F, I$ ). Neurons deprived of NGF in the presence of BAF atrophy and do not all survive long-term (Fig. 7A,D,G). Neurons deprived of NGF in the presence of CEP-1347 continued to grow for a period and then plateaued with regard to somal diameter (Fig. 7B,E,H).

CEP-1347 supported the survival of neurons after NGF deprivation, yet the metabolic rates of CEP-1347-maintained neurons were not equivalent to those of $50 \mathrm{ng} / \mathrm{ml} \mathrm{NGF}$. Realizing that 50 $\mathrm{ng} / \mathrm{ml}$ is superphysiological, we reasoned that NGF-deprived CEP-1347-maintained neurons might mimic cultures grown in concentrations of NGF $<50 \mathrm{ng} / \mathrm{ml}$. To isolate the effects of NGF on metabolism from survival, we used only concentrations of NGF that promoted survival equally but had a differential effect on metabolism. NGF promotes survival of most neurons at levels as low as $2 \mathrm{ng} / \mathrm{ml}$ (data not shown). Neurons were grown in 50 $\mathrm{ng} / \mathrm{ml}$ NGF for $5 \mathrm{~d}$. Then sister cultures were switched to $0,10,30$, or $50 \mathrm{ng} / \mathrm{ml} \mathrm{NGF}$ or 0 NGF plus CEP-1347 for $36 \mathrm{hr}$. Neurons were assessed for MTT reduction as described in Materials and Methods. Most neurons switched to 0 NGF died, and these cultures had very little MTT activity. Survival was identical among neurons switched to 10,30 , or $50 \mathrm{ng} / \mathrm{ml}$ NGF (data not shown), yet a dose-dependent stimulation of MTT activity occurred in this range. Neurons in the absence of NGF in the presence of CEP-1347 displayed MTT rates that were equivalent to cultures grown in $\sim 15 \mathrm{ng} / \mathrm{ml}$ NGF (Fig. $5 E$ ).

\section{Acute administration of CEP-1347 blocks release of cytochrome $c$ from NGF-deprived neurons; the commitment point of CEP-1347 approximates that of NGF}

Neurons were deprived of NGF for 15, 22, or 36 hr. At each time point neurons in parallel sister cultures were rescued with either NGF or CEP-1347 for $3 \mathrm{~d}$, at which times the cultures were fixed and scored for viable cells and compared with cultures that remained in NGF for the duration of the experiment. Consistent with previous reports (Deckwerth and Johnson, 1993), the commitment point for NGF was $\sim 22 \mathrm{hr}$; that is, NGF can rescue $\sim 50 \%$ of neurons when added back $22 \mathrm{hr}$ after NGF deprivation. NGF can rescue in full those neurons deprived of NGF for $15 \mathrm{hr}$. Remarkably, CEP-1347 also rescued $84 \pm 5 \%$ of neurons when administered $15 \mathrm{hr}$ after NGF deprivation but lost the ability shortly thereafter, saving only $24 \pm 7 \%$ by CEP- 1347 readdition at the $22 \mathrm{hr}$ time point (Fig. $8 A$ ). Therefore, the commitment point for CEP-1347 is $\sim 18 \mathrm{hr}$.

NGF can act at many points to abort the cell death process. For example, if NGF is added to cells that, as a population, are releasing cytochrome $c$, the release of cytochrome $c$ by neurons is aborted (Deshmukh and Johnson, 1998). The addition of CEP1347 and the inhibition of JNK signaling were able to mimic the trophic actions of NGF. Therefore, we assessed whether CEP1347 could mimic the acute actions of NGF to block cytochrome $c$ release. Neurons were deprived of NGF for $22 \mathrm{hr}$, a period at which $\sim 50 \%$ of cells have released cytochrome $c$. One plate of cells was fixed at the $22 \mathrm{hr}$ time point, whereas sister cultures were switched to either NGF-containing medium or medium lacking NGF in the presence or absence of CEP-1347 for an additional 14 hr (Fig. 8B). Of the neurons deprived of NGF for $22 \mathrm{hr}, 60 \pm 5 \%$ displayed diff use cytochrome $c$. If these neurons were not rescued (NGF-deprived for $36 \mathrm{hr}$ ), $95 \pm 3 \%$ displayed diffuse cytochrome $c$ staining. In contrast, $53 \pm 1 \%$ of NGF-rescued cells and $66 \pm$ $4 \%$ of CEP-1347-rescued neurons displayed diff use cytochrome $c$ staining. These results indicate that CEP-1347, like NGF, can abort the release of cytochrome $c$ and again demonstrate that sustained activation of the JNK pathway is required for progression of the events associated with programmed cell death.

\section{CEP-1347 can reverse the loss of cytochrome $c$, atrophy, and metabolic dysfunction of NGF-deprived caspase inhibitor-saved neurons}

NGF rescue of caspase inhibitor-saved NGF-deprived neurons is characterized by the resequestration of cytochrome $c$ into mitochondria (Martinou et al., 1999; Deshmukh et al., 2000). The resequestration requires at least two events: the de novo synthesis of cytochrome $c$ incorporated into the mitochondria and the cessation of mitochondrial permeability that facilitates efflux of cytochrome $c$ from the mitochondria. Because CEP-1347, like 

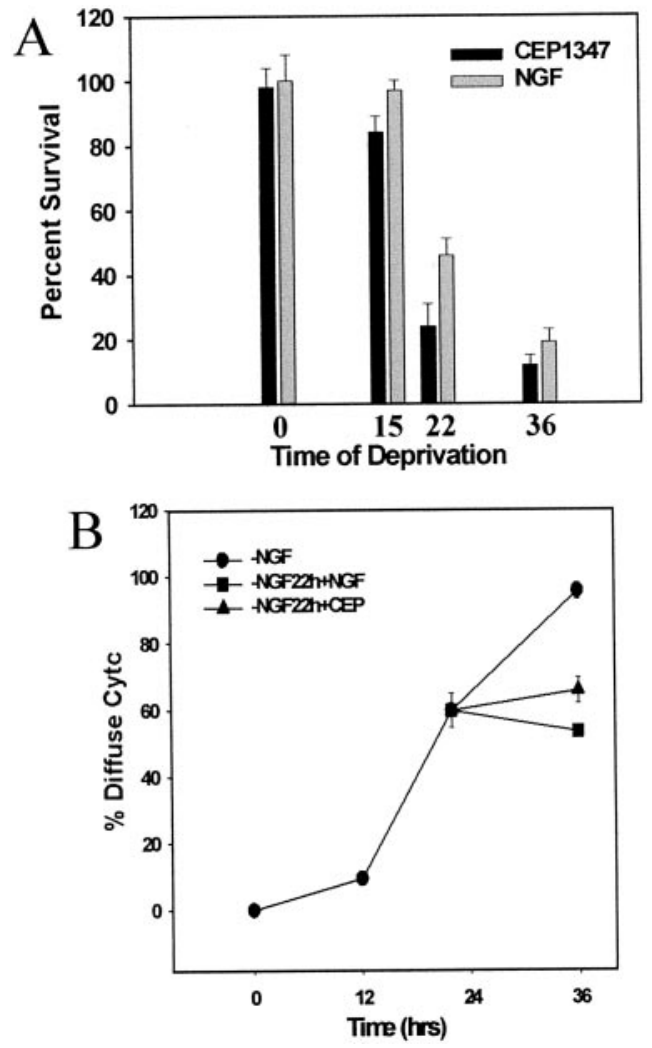

Figure 8. CEP-1347 can abort the death process: commitment point and blockade of cytochrome $c$ release. $A$, Neurons were maintained in NGF for $5 \mathrm{~d}$ and then deprived of NGF for the specified times. Then sister cultures were rescued with either NGF or CEP-1347 for $3 \mathrm{~d}$, and viability was assessed. $B$, CEP-1347 can block cytochrome $c$ release acutely. Neurons were deprived of NGF for 12, 22, or $36 \mathrm{hr}$. Sister cultures were deprived of NGF for $22 \mathrm{hr}$ and then rescued with either NGF or CEP1347 for an additional $14 \mathrm{hr}$. At $36 \mathrm{hr}, p<0.01$ for - NGF versus NGF rescue, $-\mathrm{NGF}$ versus CEP-1347 rescue.

NGF, can block acutely the release of cytochrome $c$ and can stimulate protein synthesis rates, we reasoned that long-term rescue of caspase inhibitor-saved neurons with CEP-1347 might result in resequestration of mitochondrial cytochrome $c$. To test this hypothesis, we deprived neurons of NGF for $48 \mathrm{hr}$ in the presence of the caspase inhibitor BAF and then rescued them with either NGF or CEP-1347 for $7 \mathrm{~d}$. Then the cultures were fixed and processed for cytochrome $c$ immunohistochemistry. These cultures were compared with cultures that had been maintained in NGF and with the cultures that had been deprived of NGF for $48 \mathrm{hr}$ in the presence of BAF. NGF-maintained cultures displayed punctate cytochrome $c$ in $98 \pm 1 \%$ of cells, whereas BAF-saved NGF-deprived cultures displayed punctate cytochrome $c$ staining in $9 \pm 2 \%$ of cells. Long-term rescue with both NGF and CEP-1347 resulted in immunocytochemically detectable resequestration of mitochondrial cytochrome $c$ in $67 \pm 6$ and $59 \pm 5 \%$ of cells, respectively (Fig. 9). Therefore, CEP-1347, like $\mathrm{NGF}$, can enable neurons that have lost cytochrome $c$ to resequester cytochrome $c$ in the mitochondria.

Given that CEP-1347-maintained neurons sustain the ability to synthesize proteins in the absence of NGF, we asked whether CEP-1347 could stimulate new protein synthesis in atrophied neurons that had been deprived of NGF in the presence of BAF. Neurons were deprived of NGF in the presence of BAF for 12, 24, or $48 \mathrm{hr}$. At each point of deprivation the protein synthesis rates

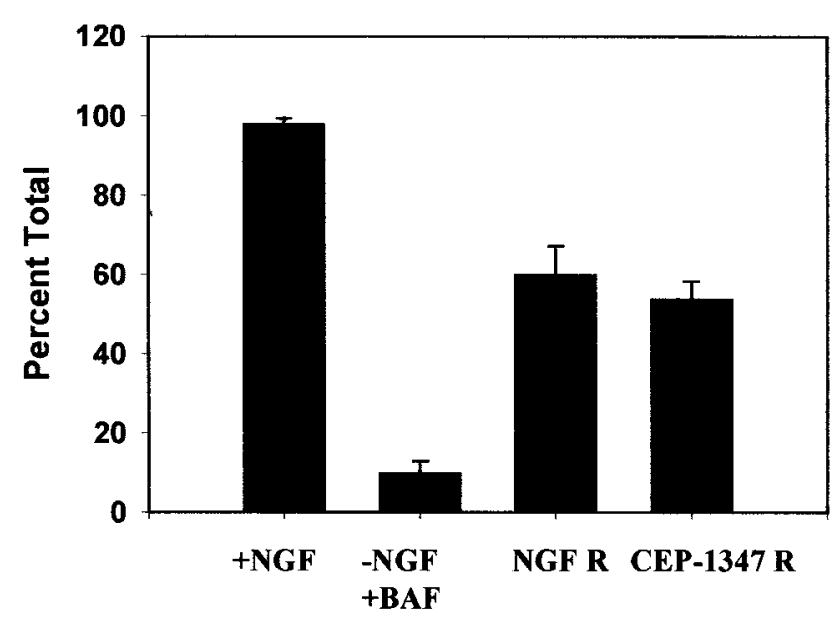

Figure 9. CEP-1347 allows atrophic neurons once again to sequester cytochrome $c$ mitochondrially. Neurons were grown in NGF for $5 \mathrm{~d}$, at which time sister parallel cultures were deprived of NGF in the presence of $\mathrm{BAF}$ for $48 \mathrm{hr}(-N G F+B A F)$. Then the deprived cultures were rescued with either NGF $(N G F R)$ or CEP-1347 (CEP-1347 R). Both NGF and CEP-1347 treatments resulted in resequestration of mitochondrial cytochrome $c ; p<0.01$ for $-\mathrm{NGF}+\mathrm{GAF}$ versus $\mathrm{NGF} \mathrm{R},-\mathrm{NGF}+\mathrm{BAF}$ versus CEP-1347 R.

were measured, and sister cultures were rescued with $50 \mathrm{ng} / \mathrm{ml}$ NGF, CEP-1347, or continued BAF treatment alone. Protein synthesis rates then were measured 2-3 d after rescue. The ability of CEP-1347 to stimulate protein synthesis was expressed as a percentage of the ability of NGF to stimulate protein synthesis in sister cultures. Neurons saved with CEP-1347 at the time of deprivation displayed protein synthesis rates $\sim 75 \%$ of those maintained in NGF. The ability of CEP-1347 to stimulate protein synthesis was maintained in cultures that had been deprived of NGF for $12 \mathrm{hr}$ at a level $\sim 70 \%$ of NGF rescue. However, between 12 and $24 \mathrm{hr}$ after NGF deprivation there was a change in the neurons such that the subsequent readdition of CEP-1347 was able to promote only $50 \%$ of the stimulated protein synthesis that NGF can stimulate (Fig. 10A). By $48 \mathrm{hr}$ this level was decreased to $\sim 40 \%$. Therefore, CEP-1347 can rescue protein synthesis rates in neurons deprived of NGF but kept alive by caspase inhibitors, although not to the same extent as $50 \mathrm{ng} / \mathrm{ml} \mathrm{NGF}$.

To determine whether CEP-1347 could reverse atrophy of neurons deprived of NGF that had been saved by caspase inhibitors, we measured somal diameters of sympathetic neurons after $5 \mathrm{~d}$ in culture. At this time they have an average somal diameter of $18.6 \mu \mathrm{m}$. Neurons then were deprived of NGF for $4 \mathrm{~d}$ in the presence of BAF. During this NGF deprivation the neurons atrophied considerably, displaying an average somal diameter of $15.3 \pm 0.5 \mu \mathrm{m}$ after $4 \mathrm{~d}$ of deprivation. At this time sister cultures were rescued with NGF (50 ng/ml), CEP-1347, or continued BAF alone. Neurons that remained in BAF remained atrophied (Deshmukh et al., 1996) (data not shown). In contrast, NGF-rescued neurons grew rapidly to attain an average somal diameter of $22.6 \pm 0.6 \mu \mathrm{m}$ in $7 \mathrm{~d}$ for a growth rate of $1.04 \mu \mathrm{m} / \mathrm{d}$. CEP-1347rescued neurons displayed an intermediate growth rate, attaining an average somal diameter of $17.5 \pm 0.73 \mu \mathrm{m}$ for a growth rate of $0.31 \mu \mathrm{m} / \mathrm{d}$, a value $30 \%$ of the $50 \mathrm{ng} / \mathrm{ml} \mathrm{NGF-rescued} \mathrm{neurons}$ (Fig. 10B). Therefore, CEP-1347 not only can prevent but also can reverse the atrophy associated with trophic factor withdrawal. 


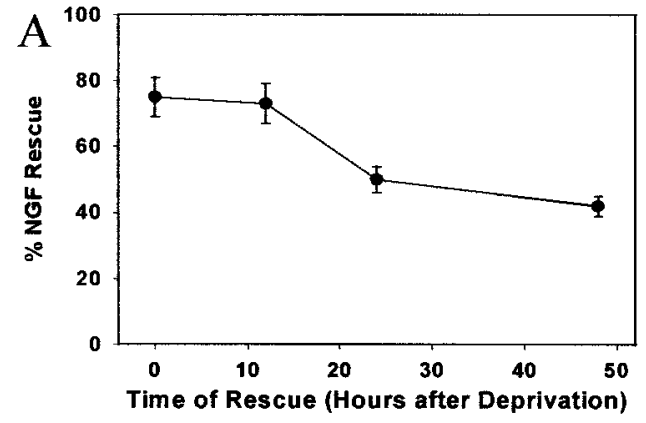

B

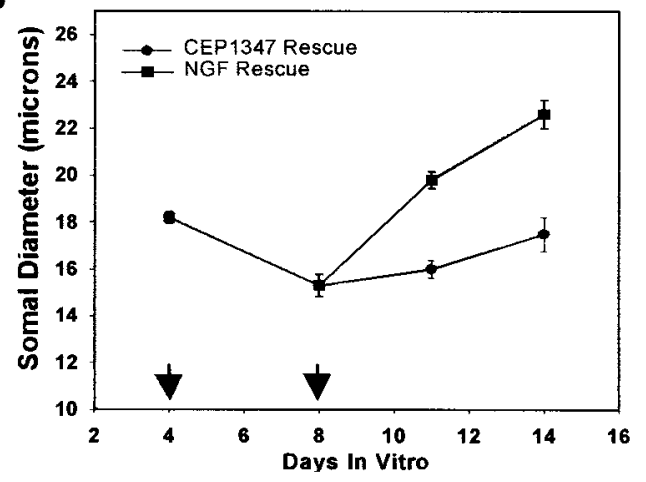

Figure 10. CEP-1347 can reverse somal atrophy and dysfunction. $A$, Neurons were deprived of NGF for 12,24 , or $48 \mathrm{hr}$ in the presence of BAF. At each time point sister cultures were rescued with either NGF or CEP-1347 for 2-3 d. The ability of CEP-1347 to rescue protein synthesis is plotted as a function of the time of deprivation. The protein synthesis rates acquired by NGF-rescued neurons were set at $100 \%$, whereas the rate for neurons receiving no rescue (treatment with BAF alone) was set to $0 \%$. B, CEP-1347 can promote the growth of atrophic neurons. Neurons were deprived of NGF in the presence of BAF for $4 \mathrm{~d}$, at which time sister cultures were rescued with either NGF or CEP-1347. Subsequently, somal diameter was determined; $p<0.05$ for $t=14 \mathrm{~d}$ CEP-1347 rescue versus $8 \mathrm{~d}$.

\section{DISCUSSION}

CEP-1347, a selective inhibitor of MLKs, acts as an inhibitor of MLK-mediated JNK activation. As such, it has great value as an experimental tool to elucidate the role of JNK pathway activation in cellular processes in which MLKs are the primary mediators of JNK activation. CEP-1347 is a potent inhibitor of neuronal death in several in vivo and in vitro paradigms (Borasio et al., 1998; Maroney et al., 1998; Saporito et al., 1999). The results reported here confirm that CEP-1347 inhibits MLK-mediated MKK4 phosphorylation and subsequent JNK activation in NGFdeprived sympathetic neurons (Maroney et al., 1999) and provides long-term protection from death. Our lab has characterized the metabolic and functional status of these cells extensively when death is prevented by caspase inhibitors or Bax deletion. We have shown previously that inhibiting death at these points in the pathway does not prevent the loss of metabolic function or the atrophy associated with NGF deprivation (Deshmukh et al., 1996; Deckwerth et al., 1998). Indeed, caspase inhibitors act downstream of cytochrome $c$ release and retard, but do not prevent permanently, cell death (Deshmukh et al., 2000). Bax deletion prevents cytochrome $c$ release and prevents death long-term. In contrast to these neuroprotective strategies, treatment with CEP1347 not only prevents death long-term but also maintains metabolic function and somal growth after NGF deprivation. Remarkably, the addition of CEP-1347 to caspase inhibitor-saved
NGF-deprived neurons, even after the loss of mitochondrial cytochrome $c$, results in restoration of metabolic function, somal growth, and the reestablishment of sequestration of mitochondrial cytochrome $c$. Thus, sustained activation of the JNK pathway not only is required for the cell death associated with NGF deprivation but also is required for the metabolic dysfunction associated with trophic factor withdrawal. Continued activation of the pathway is required for the maintenance of the atrophic state and the rendering of mitochondria unable to sequester cytochrome $c$. In other words, a major mechanism by which neurotrophic factors are trophic is their ability to suppress JNK activation.

\section{CEP-1347 is a potent neuroprotectant that blocks MLK-mediated JNK activation}

Our study demonstrates that CEP-1347 can abort the cell death pathway at times later than JNK activation in neurons deprived of NGF. Peak JNK activities occur $4 \mathrm{hr}$ after NGF deprivation when assayed by in vitro kinase reactions (Virdee et al., 1997). Yet very few neurons go on to die when rescued by the JNK pathway inhibitor CEP-1347 at $15 \mathrm{hr}$ after NGF deprivation, a time much later than when a majority of the neurons are phospho-c-Junpositive. Therefore, CEP-1347 can act to prevent death at times significantly later than the activation of its target. These observations indicate that sustained $\mathrm{JNK}$ activation for a period of several hours is needed to commit neurons to die.

CEP-1347 recently was demonstrated to inhibit specifically the mixed lineage kinase family of kinases (Maroney et al., 2001). MLKs are known activators of JNK signaling by activating JNK kinases MKK4 and MKK7. Importantly, CEP-1347 does not inhibit JNK activation by ASK-1 or MEKK1 (Maroney et al., 2001), two stress-activated protein kinases (SAPKKK) previously implicated in neuronal death (Eilers et al., 1998; Kanamoto et al., 2000). The ability of CEP-1347 to block MLK-mediated JNK activation and its inability to block activation mediated by ASK1 and MEKK1 strongly suggest that MLKs are the physiologically relevant activators of JNK in neurons undergoing programmed cell death.

\section{NGF-deprived neurons maintain metabolic activity in the presence of CEP-1347}

The data reported here demonstrate that the metabolic depression that occurs after withdrawal of trophic factor from neurons can be reduced significantly with the administration of the JNK pathway inhibitor CEP-1347. The protein synthesis rates, mitochondrial dehydrogenase activities, and glucose uptake rates are all significantly greater after NGF deprivation in the presence of CEP-1347 compared with the caspase inhibitor BAF. Furthermore, the metabolic depression is not a result of the loss of cytochrome $c$ that occurs when neurons are deprived of NGF in the presence of BAF. Nearly identical falls in metabolic activity occur in Bax-deficient neurons deprived of NGF compared with neurons deprived of NGF in the presence of caspase inhibitors (Deshmukh et al., 1996; Deckwerth et al., 1998). Therefore, metabolic depression occurs as a result of signaling events downstream of CEP-1347 action and upstream of BAX function.

The growth rates of NGF-deprived CEP-1347-maintained cells are indistinguishable from those maintained in $50 \mathrm{ng} / \mathrm{ml} \mathrm{NGF}$ for several days. However, during this period the metabolic rates of neurons in these groups are not equal. The protein synthesis rates, mitochondrial activity, and glucose uptake rates are all approximately two-thirds of that maintained in $50 \mathrm{ng} / \mathrm{ml} \mathrm{NGF}$ 

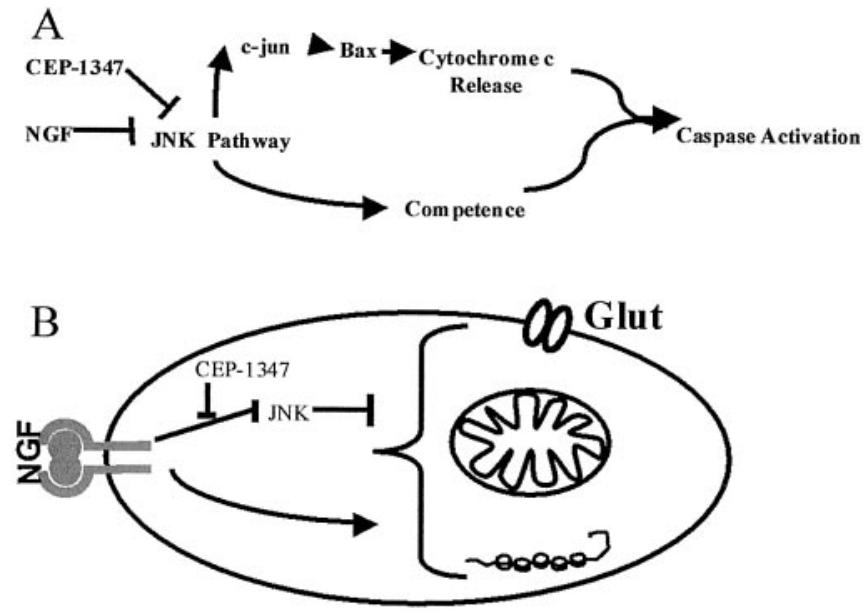

Figure 11. CEP-1347 blocks cell death, and JNK acts upstream of the divergence of cell death pathways. $A$, CEP-1347 blocks the development of competence-to-die by cytochrome $c$ and the Bax-dependent release of cytochrome $c$, which cooperate to activate caspases. $B$, NGF regulates metabolism via both activating and inhibiting signaling pathways. Stimulation of metabolism appears to result from the inhibition of JNK signaling because NGF-deprived neurons display active metabolic rates in the presence of the JNK inhibitor CEP-1347. A second pathway independent of JNK activation would account for the difference between NGFmaintained cultures and NGF-deprived CEP-1347-maintained neurons. Here metabolism is represented by polysomes (right bottom, protein synthesis), mitochondrial activity (right center), and glucose uptake (right top, Glut, a glucose transporter).

(although presumably equivalent to $100 \%$ of the anabolism of cultures maintained in $\sim 15 \mathrm{ng} / \mathrm{ml} \mathrm{NGF}$; Fig. $5 E$ ). This ability to maintain growth for several days is likely attributable to the fact that neurons are able to couple protein synthesis and degradation in the presence of trophic support (Franklin and Johnson, 1998). Future studies will address whether inhibition of the JNK pathway with CEP-1347 in fact can maintain the coupling of the rates of protein synthesis and degradation and allow neurons with varying metabolic rates to grow at similar rates.

These studies have unmasked different components of metabolic activity (Fig. 11B). The first approximately one-third of metabolic rate is the basal metabolism of neurons in the absence of trophic support. A paradigm for assessing this pool is neurons isolated from Bax-deficient animals deprived of NGF. The second component of metabolic activity comes from repressing the JNK pathway in cells. Finally, neurons maintained at high levels of NGF display a third component of metabolism. The molecular basis for this third pool is unknown but does not appear to be via the Erk-MAPK signaling pathway because it was not ablated by the MEK1 inhibitor U0126 (data not shown). It is possible that the third component is stimulated via the PI3kinase-Akt signaling axis.

It is not clear how inhibition of the JNK pathway results in increased metabolism or, in other words, how activation of the JNK pathway results in metabolic depression. With regard to protein synthesis a candidate mediator is the p70 S6 kinase, which phosphorylates the ribosomal S6 protein, a constituent of the 40S subunit. Phosphorylation of p70 S6 positively regulates transcription of mRNAs with $5^{\prime}$ oligopyrimidine tracts (5'TOP). Another possible signaling mechanism to regulate protein synthesis is the phosphorylation of eukaryotic initiation factor $2 \alpha$ (EIF2 $\alpha$ ). EIF2 $\alpha$ becomes phosphorylated in response to diverse stress stimuli, including viral infection, heat shock, nutrient limitation, or endoplasmic reticulum stress (Hershey et al., 1996). Phosphorylated EIF2 $\alpha$ lowers cellular protein synthesis rates by inhibiting the association of Met-tRNAi with the 40S ribosomal subunit. Little is known about the regulation of glucose transport in neurons. Glucose is transported via the facilitative glucose transporters. In skeletal muscle and adipocytes the glucose uptake rates are regulated by the movement of membrane vesicles containing Glut-4 glucose transporters to the plasma membrane (Rodnick et al., 1992). Neurons primarily possess the Glut-3 transporter with some Glut-1 (Vannucci et al., 1997). Glut-3 might be regulated directly by phosphorylation at the plasma membrane as occurs for the Glut-2 transporter in pancreatic $\beta$-cells (Thorens et al., 1996).

A primary role for $\mathrm{JNKs}$ seems to be activation of transcription factors such as c-Jun. However, our data along with recent data demonstrating that JNK deficiency eliminates cell death in response to UV irradiation (Tournier et al., 2000), a paradigm that is not dependent on macromolecular synthesis, are suggestive that JNK pathway enzymes may have nontranscriptional effector mechanisms. JNK may have physiologically relevant substrates in addition to the transcription factor c-Jun.

\section{CEP-1347 can reverse, as well as prevent, the catabolic effects of NGF deprivation}

Another striking observation is that inhibition of the JNK pathway can result in the reversal of metabolic dysfunction in neurons that have been deprived of NGF in the presence of the pancaspase inhibitor BAF. CEP-1347 was able to promote growth in these neurons. Protein synthesis also can be rescued by CEP-1347 in a time-dependent manner. Therefore, it appears that the JNK pathway can act as a switch in neurons to regulate metabolism. Activation of JNK results in metabolic depression, whereas JNK inhibition results in metabolic stimulation. JNK activity is required for initiation and maintenance of the atrophic state of dysf unctional neurons.

\section{CEP-1347 blocks the development of competence-to-die}

NGF-maintained neurons do not die in response to cytochrome $c$ microinjection. Bax-deficient neurons and $\mathrm{CHX}$-saved neurons do not die with NGF deprivation, but these NGF-deprived neurons do die in response to intracellular injection of cytochrome $c$ (Deshmukh and Johnson, 1998). These experiments unmasked a parallel pathway, known as competence-to-die, the activation of which is required for caspase activation in neurons. Our results show that neurons deprived of NGF in the presence of CEP-1347 did not die after injection of cytochrome $c$. Therefore, NGFdeprived CEP-1347-maintained neurons are incompetent to die as a result of cytosolic cytochrome $c$. Although the exact nature of competence is unknown, these results implicate the JNK pathway as critical to regulating the development of competence. These results do not discriminate between JNK pathway enzymes directly phosphorylating or indirectly regulating the function of apoptosome components in neurons. However, it is clear that the site of CEP-1347 action, MLK activation, is upstream of the bifurcation between the parallel pathways leading to cytochrome $c$ release and the development of competence (Fig. 11A).

Much attention has been given to the role of JNK pathway enzymes in promoting cell death, with little attention on its regulation of metabolism. Neuronal dysfunction preceding neuronal loss is thought to occur in vivo in many neurodegenerative diseases. This "quality of life" issue must be considered in addition to the life or death of neurons. Although caspase inhibitors 
have potential in acute clinical settings, they are unlikely to be an effective monotherapy in chronic conditions, given that caspase inhibitor-saved cells are dysfunctional. The existence of a neuroprotectant that can preserve functionality of neurons in addition to keeping them alive may offer advantages in the treatment of chronic neurodegenerative disease.

\section{REFERENCES}

Borasio GD, Horstmann S, Anneser JM, Neff NT, Glicksman MA (1998) CEP-1347/KT7515, a JNK pathway inhibitor, supports the in vitro survival of chick embryonic neurons. NeuroReport 9:1435-1439.

Deckwerth TL, Johnson Jr EM (1993) Temporal analysis of events associated with programmed cell death (apoptosis) of sympathetic neurons deprived of nerve growth factor. J Cell Biol 123:1207-1222.

Deckwerth TL, Easton RM, Knudson CM, Korsmeyer SJ, Johnson Jr EM (1998) Placement of the BCL-2 family member BAX in the death pathway of sympathetic neurons activated by trophic factor deprivation. Exp Neurol 152:150-162.

Deshmukh M, Johnson Jr EM (1998) Evidence of a novel event during neuronal death: development of competence-to-die in response to cytoplasmic cytochrome $c$. Neuron 21:695-705.

Deshmukh M, Vasilakos J, Deckwerth TL, Lampe PA, Shivers BD, Johnson Jr EM (1996) Genetic and metabolic status of NGF-deprived sympathetic neurons saved by an inhibitor of ICE family proteases. J Cell Biol 135:1341-1354.

Deshmukh M, Kuida K, Johnson Jr EM (2000) Caspase inhibition extends the commitment to neuronal death beyond cytochrome $c$ release to the point of mitochondrial depolarization. J Cell Biol 150:131-144.

Easton RM, Deckwerth TL, Parsadanian AS, Johnson Jr EM (1997) Analysis of the mechanism of loss of trophic factor dependence associated with neuronal maturation: a phenotype indistinguishable from Bax deletion. J Neurosci 17:9656-9666.

Eilers A, Whitfield J, Babij C, Rubin LL, Ham J (1998) Role of the Jun kinase pathway in the regulation of c-jun expression and apoptosis in sympathetic neurons. J Neurosci 18:1713-1724.

Encinas M, Tansey MG, Tsui-Pierchala BA, Comella JX, Milbrandt J, Johnson Jr EM (2001) c-Src is required for glial cell line-derived neurotrophic factor (GDNF) family ligand-mediated neuronal survival via a phosphatidylinositol-3 kinase (PI-3K)-dependent pathway. J Neurosci 21:1464-1472.

Estus S, Zaks WJ, Freeman RS, Gruda M, Bravo R, Johnson Jr EM (1994) Altered gene expression in neurons during programmed cell death: identification of c-jun as necessary for neuronal apoptosis. J Cell Biol 127:1717-1727.

Franklin JL, Johnson Jr EM (1998) Control of neuronal size homeostasis by trophic factor-mediated coupling of protein degradation to protein synthesis. J Cell Biol 142:1313-1324.

Ham J, Babij C, Whitfield J, Pfarr CM, Lallemand D, Yaniv M, Rubin LL (1995) A c-jun dominant-negative mutant protects sympathetic neurons against programmed cell death. Neuron 14:927-939.

Hershey J, Mathews M, Sonenberg N, Cold Spring Harbor Laboratory (1996) Translational control. Plainview, NY: Cold Spring Harbor Laboratory.

Johnson MI, Argiro V (1983) Techniques in the tissue culture of rat sympathetic neurons. Methods Enzymol 103:334-347.

Kanamoto T, Mota M, Takeda K, Rubin LL, Miyazono K, Ichijo H, Bazenet CE (2000) Role of apoptosis signal-regulating kinase in reg- ulation of the c-Jun N-terminal kinase pathway and apoptosis in sympathetic neurons. Mol Cell Biol 20:196-204.

Liu Y, Peterson DA, Kimura H, Schubert D (1997) Mechanism of cellular 3-(4,5-dimethylthiazol-2-yl)-2,5-diphenyltetrazolium bromide (MTT) reduction. J Neurochem 69:581-593.

Maroney AC, Glicksman MA, Basma AN, Walton KM, Knight Jr E, Murphy CA, Bartlett BA, Finn JP, Angeles T, Matsuda Y, Neff NT, Dionne CA (1998) Motoneuron apoptosis is blocked by CEP-1347 (KT7515), a novel inhibitor of the JNK signaling pathway. J Neurosci 18:104-111.

Maroney AC, Finn JP, Bozyczko-Coyne D, O'Kane TM, Neff NT, Tolkovsky AM, Park DS, Yan CY, Troy CM, Greene LA (1999) CEP-1347 (KT7515), an inhibitor of JNK activation, rescues sympathetic neurons and neuronally differentiated PC12 cells from death evoked by three distinct insults. J Neurochem 73:1901-1912.

Maroney AC, Finn JP, Connors TJ, Durkin JT, Angeles T, Gessner G, Xu Z, Meyer SI, Savage MJ, Greene LA, Scott RW, Vaught JL (2001) CEP-1347 (KT7515), a semisynthetic inhibitor of the mixed lineage kinase family. J Biol Chem 276:25302-25308.

Martin DP, Schmidt RE, DiStefano PS, Lowry OH, Carter JG, Johnson Jr EM (1988) Inhibitors of protein synthesis and RNA synthesis prevent neuronal death caused by nerve growth factor deprivation. J Cell Biol 106:829-844.

Martinou I, Desagher S, Eskes R, Antonsson B, Andre E, Fakan S, Martinou JC (1999) The release of cytochrome $c$ from mitochondria during apoptosis of NGF-deprived sympathetic neurons is a reversible event. J Cell Biol 144:883-889.

Neame SJ, Rubin LL, Philpott KL (1998) Blocking cytochrome $c$ activity within intact neurons inhibits apoptosis. J Cell Biol 142:1583-1593.

Nicholls DG, Ward MW (2000) Mitochondrial membrane potential and neuronal glutamate excitotoxicity: mortality and millivolts. Trends Neurosci 23:166-174

Oppenheim RW (1991) Cell death during development of the nervous system. Annu Rev Neurosci 14:453-501.

Putcha GV, Deshmukh M, Johnson Jr EM (1999) BAX translocation is a critical event in neuronal apoptosis: regulation by neuroprotectants, BCL-2, and caspases. J Neurosci 19:7476-7485.

Recio-Pinto E, Rechler MM, Ishii DN (1986) Effects of insulin, insulinlike growth factor II, and nerve growth factor on neurite formation and survival in cultured sympathetic and sensory neurons. J Neurosci 6:1211-1219.

Rodnick KJ, Slot JW, Studelska DR, Hanpeter DE, Robinson LJ, Geuze HJ, James DE (1992) Immunocytochemical and biochemical studies of GLUT-4 in rat skeletal muscle. J Biol Chem 267:6278-6285.

Saporito MS, Brown EM, Miller MS, Carswell S (1999) CEP-1347/ KT7515, an inhibitor of c-Jun N-terminal kinase activation, attenuates the 1-methyl-4-phenyl tetrahydropyridine-mediated loss of nigrostriata dopaminergic neurons in vivo. J Pharmacol Exp Ther 288:421-427.

Thorens B, Deriaz N, Bosco D, DeVos A, Pipeleers D, Schuit F, Meda P, Porret A (1996) Protein kinase A-dependent phosphorylation of GLUT-2 in pancreatic beta cells. J Biol Chem 271:8075-8081.

Tournier C, Hess P, Yang DD, Xu J, Turner TK, Nimnual A, Bar-Sagi D, Jones SN, Flavell RA, Davis RJ (2000) Requirement of JNK for stress-induced activation of the cytochrome $c$-mediated death pathway. Science 288:870-874.

Vannucci SJ, Maher F, Simpson IA (1997) Glucose transporter proteins in brain: delivery of glucose to neurons and glia. Glia 21:2-21.

Virdee K, Bannister AJ, Hunt SP, Tolkovsky AM (1997) Comparison between the timing of JNK activation, c-Jun phosphorylation, and onset of death commitment in sympathetic neurones. J Neurochem 69:550-561. 